\title{
Hegel y la crítica de la economía política del colonialismo. La recepción de un debate inconcluso.
}

\author{
Angelo A. Narváez León ${ }^{1}$ \\ Pablo C. Pulgar Moya²
}

Recibido: 17 de junio de 2019 - Aceptado: 5 de agosto de 2019

\begin{abstract}
Resumen
El presente artículo tiene como propósito poner en diálogo las diferentes interpretaciones y lecturas sobre el fenómeno del colonialismo en la obra de Hegel. Ante una diversidad de tratamientos exegéticos sobre este concepto, postulamos que su desarrollo viene aparejado con la dilucidación del rol que juega en Hegel una clarificación del capitalismo como momento hegemónico del capital. Para ello intentamos reconstruir el debate que se desprende sobre el rol de estos términos, tanto dentro de la tradición hegeliana como en la interpretación marxista. Hemos de reconocer que, si bien Hegel nunca redactó teoría alguna del capital, podemos derivar un tratamiento crítico a los fenómenos de la economía política, entre los cuales colonialismo e imperialismo aparecen como integrantes fundamentales.
\end{abstract}

Palabras clave: Hegel - capitalismo - colonialismo - economía política capital

1 Chileno. Profesor de Filosofía, Licenciado en Educación, Licenciado en Filosofía y Doctor en Filosofía por la Pontificia Universidad Católica de Valparaíso. Investigador posdoctoral, Pontificia Universidad Católica de Valparaíso. Contacto: angelo. narvaez.|@gmail.com

ORCID: https://orcid.org/0000-0001-7320-6905

2 Chileno. Profesor de Filosofía, Licenciado en Educación por la Pontificia Universidad Católica de Valparaíso. Doctor en Filosofía por la Ruprecht-Karls-Universität Heidelberg. Docente del Departamento de Historia y Geografía, Universidad de Santiago. Contacto: pablo.pulgar.m@hotmail.com

ORCID: https://orcid.org/0000-0002-9594-2070 


\title{
Hegel and critique of the political economics of colonialism. Reception of an ongoing debate.
}

\begin{abstract}
Summary
The purpose of this article is to strike a dialog between the different interpretations and readings about the phenomenon of colonialism found in the works of Hegel. Faced with a wide range of exegetical treatments of this concept, we postulate that its development goes hand in hand with the dilucidation of the role that Hegel plays in clarifying capitalism as a hegemonic moment of capital. We therefore set out to reconstruct the debate that has been spurred over the role of these terms, both within the Hegelian tradition and under a Marxist interpretation. We must recognize that, although Hegel never published any theory on capital, we can derive a critical treatment of the phenomena of political economics, in which colonialism and imperialism appear as fundamental components.
\end{abstract}

Keywords: Hegel - capitalism - colonialism - political economics - capital

\section{Hegel e a crítica da economia política do colonialismo. A recepção de um debate inconcluso}

\begin{abstract}
Resumo
O presente artigo possui como propósito iniciar um diálogo sobre as diferentes interpretações e leituras do fenômeno do colonialismo na obra de Hegel. Diante de uma diversidade de tratamentos exegéticos deste conceito, postulamos que seu desenvolvimento vem acompanhado da elucidação do papel que desempenha em Hegel um esclarecimento do capitalismo como momento hegemônico do capital. Para isto tentamos reconstruir o debate gerado sobre o papel destes termos, tanto dentro da tradição hegeliana quanto da interpretação marxista. Temos que reconhecer que, embora Hegel nunca elaborou teoria alguma sobre o capital, podemos derivar um tratamento crítico aos fenômenos da economia política, dentre os quais colonialismo e imperialismo aparecem como integrantes fundamentais.
\end{abstract}

Palavras-chave: Hegel - capitalismo - colonialismo - economia política capital

\section{Introducción}

Los orígenes del capitalismo han sido discutidos históricamente desde múltiples prismas e interpretaciones que, muchas veces, han puesto 
el énfasis en la posición hegemónica del capital como forma social, antes que en su existencia empírica. Giovanni Arrighi, por ejemplo, insiste en los orígenes comerciales del capitalismo en el norte italiano, particularmente en Venecia y Florencia (Arrighi 25). Max Weber, por su parte, argumenta que los orígenes genealógicos del capitalismo pueden ser rastreados a través de las reformas protestantes europeas, hasta la subversión del orden eclesiástico atisbado por Lutero, proceso en que, paulatinamente, "la fuerza emanada de la concepción puritana de la vida no propició únicamente la creación de capitales, [sino,] además, dio resultados aún de mayor importancia, al beneficiar de manera especial la formación del comportamiento burgués y racional" $y$, subsecuentemente, a la centralidad del homo oeconomicus en el mundo moderno (Weber 224). Ya avanzado el siglo XIX, Karl Polanyi argumentará que el capitalismo, como práctica y no solo como discurso, se debe a una profunda modificación del sistema comercial internacional, conducido ahora por un mercado de capitales inaugurado en Inglaterra entre la tercera y cuarta década del siglo XIX (Polanyi 137). Lo que tienen en común estas tres interpretaciones, a pesar de sus diferencias, estriba en el énfasis histórico de la transformación económica de la modernidad. Sin embargo, existen otras propuestas que han privilegiado el análisis de los mecanismos de esa misma transformación.

Adam Smith sostenía, a fines del siglo XVIII —en su célebre hipótesis—, que la diferencia específica de los sistemas comerciales modernos estribaba en los alcances sociales de una división social sistemática de los procesos productivos, tanto a nivel nacional como internacional, amparados en una tecnificación ascendente de esta misma división a través de la industrialización (Smith 28). Esta hipótesis, sin embargo, sería puesta en cuestión por Émile Durkheim, al sostener éste que, si bien existe una división social específicamente capitalista del trabajo, no toda división social del trabajo representa estructuralmente una dimensión capitalista en la historia de las sociedades, aun cuando estén determinadas por algún índice de industrialización (Durkheim 37). Eric Hobsbawm intentó, a lo largo del siglo XX, situar ambas perspectivas en un horizonte común, relativizando ambos énfasis. No se tratará tanto de situar el origen local del capitalismo, ni de 
evidenciar ciertos mecanismos particulares, sino de conceptualizar su comportamiento lógica e históricamente. Desde esta perspectiva, sostiene Hobsbawm, el capitalismo inauguró una cosmovisión en la cual la revolución permanente de los medios de producción y de la singularidad de los sistemas sociales se transformaría en su norma de supervivencia (Hobsbawm 35).

A pesar de sus diferencias, estas hipótesis comparten un sistema de coordenadas común; a saber, que la formación y hegemonización del capitalismo, como sistema integral de relaciones sociales, anticipó empíricamente a sus formalizaciones conceptuales. Es decir, no solo el capital y las relaciones capitalistas existen antes del capitalismo, sino que éste existe antes que tal o cual formalización conceptual que pretenda dar cuenta de sus orígenes y alcances. Sin embargo, en el proceso de conformación y hegemonización del capitalismo en un nivel global es posible identificar un proceso de inflexión que radica en el vuelco del siglo XVIII al siglo XIX, años en los cuales surgieron significaciones conceptuales y categoriales, cuya finalidad no era otra que la interpretación de la transformación del presente: "capitalismo", "clases sociales" y "valor", pero también "socialismo", "comunismo" y "sindicato", son categorías que surgen históricamente a lo largo de este proceso. Y es que, como sostiene Hobsbawm, el siglo XIX representa un proceso en el cual la sociedad europea se enfrenta a la necesidad de verbalizar y conceptualizar las condiciones materiales de su propia transformación, pues "la gran revolución de 1789-1848 fue el triunfo, no de la "industria" como tal, sino de la industria "capitalista"; no de la libertad y la igualdad en general, sino de la "clase media" o sociedad "burguesa y liberal" (Hobsbawm 9). En este escenario, el concepto de "economía política", como también la correspondiente crítica de la economía política, adquieren un sentido específicamente capitalista. En la presente investigación abordaremos cómo, en el contexto de la filosofía hegeliana del Derecho, surge una propuesta filosófica de la representación de la dimensión económica de la modernidad, y cómo, a la vez, esa misma representación da paso a la postulación de una crítica de la economía política. La tensión entre ambos conceptos es crucial en el armazón teórico del presente trabajo, pues presenta la posibilidad de interpretar el desarrollo conceptual 
de Hegel ya como descripción autodesplegante de los momentos de la economía política, o como tratamiento escéptico de estos mismos.

\section{Hegel y la economía política del capitalismo}

De entre las dos grandes transformaciones del periodo revolucionario de 1789-1848, la revolución "política" francesa ha corrido con amplia ventaja dentro los márgenes de los estudios hegelianos, en directo detrimento de una ocupación continua y sistemática de la influencia de la revolución "económica" inglesa. En este escenario, estudios como el de Fredrick Beiser han llegado a sostener que la economía política no representa más que un espacio insignificante en la amplitud de la filosofía hegeliana (Beiser 243). Desde una posición diametralmente opuesta, Denis Rosenfield sostiene que, a los ojos de Hegel, "las diferentes teorías del contrato social [fueron] refutadas prácticamente por los hechos revolucionarios"; estos, insiste Rosenfield, produjeron "condiciones sociales, económicas y políticas que [pusieron] de relieve la falta de adecuación entre este pensamiento político y el despliegue de la realidad efectiva" (Rosenfield 170). El "nuevo mundo" que se abría paso tras 1789 no se reducía a una transformación estrictamente política, sino que encontró en la revolución económica las condiciones de posibilidad de su propia transformación. Y así, concluye también Rosenfield, "Hegel se dedica a estudiar en esas circunstancias tales condiciones socioeconómicas, cuyo cercano ejemplo de Inglaterra, hija de la Revolución industrial, le proporciona no solamente otro enfoque histórico, sino que le da también la ocasión de hallar una ciencia (la economía política), que expresa mejor lo que está por pasar" (Ibíd). Así también lo entiende Manfred Riedel al insistir en que, "encontrando a la economía política, Hegel comprende ahora que la revolución política misma y su idea central de libertad pertenecen históricamente al advenimiento de la nueva sociedad" (Ibíd).

Una de las primeras aproximaciones que pretendió dar cuenta de la profundidad específica de la economía política en la filosofía hegeliana fue elaborada por Georgi Plejánov, a fines del siglo XIX. En su opúsculo, Plejánov sostiene que, si bien Hegel "poco se ocupó [como Marx, se 
subentiende] de la economía política", su genio "le ayudó a captar el aspecto más característico y esencial de los fenómenos [...] más claramente que todos los economistas de su tiempo, sin exceptuar a David Ricardo" (Plejánov 153). Para Claudio Lomnitz, por ejemplo, la filosofía hegeliana no solo enfrenta los procesos socioeconómicos de su tiempo, sino que más bien esta misma filosofía deriva de la necesidad de conceptualización de los problemas abiertos por la economía política moderna. Así, insiste Lomnitz en su introducción a Hegel, Haití y la historia universal de Susan Buck-Morss, que

El problema central de Hegel viene en buena parte de Adam Smith. Se trata de un problema que tiene mucho de contemporáneo; la incompatibilidad entre la dinámica del mercado de libre competencia y el ideal de nación, como una colectividad emancipada y soberana. Se trata de una contradicción entre la tendencia a la especialización laboral, dictada por la competencia de mercado — con su tendencia consiguiente a la degradación del trabajador, hasta convertirlo en una máquina de trabajo rutinizado-y el progreso humano colectivo (10).

Y así también lo entiende Georg Lukács:

Hegel es no solo el filósofo que más profunda y adecuada comprensión tiene en Alemania de la esencia de la Revolución francesa y del periodo napoleónico, sino, además, el único pensador alemán del periodo que se ha ocupado seriamente de los problemas de la Revolución industrial ocurrida en Inglaterra, y el único que por entonces puso en relación los problemas de la economía clásica inglesa con los problemas de la filosofía de la dialéctica (29).

José Aricó, por su parte, insistirá en la hipótesis de Lukács al sostener que "Hegel introdujo en el ámbito específico alemán las aportaciones de los economistas ingleses" (Aricó 16). Ahora bien, para la tradición marxista occidental, la relación de Hegel con la economía política se enmarca dentro de un orden formal y metodológico, carente de cualquier alcance propio en el ámbito de una crítica posible de la 
economía política. Así, por ejemplo, para Lukács, se trata formalmente de comprender "[...] la conexión interna entre filosofía y economía, entre economía y dialéctica" (Lukács 31) y, metodológicamente, de comprender la fetichización de las categorías propias de las ciencias sociales como reflejo ideológico de las condiciones materiales de existencia. A esta misma tesis, formal y metodológica, adhiere Marcuse al sostener que, "La transición de Hegel a Marx es [...] la transición a un orden de verdad esencialmente diferente, [...] todos los conceptos filosóficos de la teoría marxista son categorías sociales y económicas, mientras que las categorías sociales y económicas de Hegel son todas conceptos filosóficos" (Marcuse 259).

Este juicio, ampliamente difundido a través de una lectura particular de las proposiciones metodológicas esgrimidas por Marx en el epílogo a la segunda edición alemana de El capital, y en la Introducción a la crítica de la economía política de 1857, supuso una interpretación excluyente de la representación hegeliana de la economía política, en la cual la posibilidad de una crítica de ésta figuraba como formal y metodológicamente imposible $y$, por tanto, materialmente inexistente. En gran medida, la extensión de este juicio supuso además el imperativo del marxismo, aún hoy presente, por centrar parte de sus debates en torno al "método hegeliano". Sin embargo, esta no ha sido la única aproximación al problema.

Para Birger Priddat, en Hegel no solo hay una recepción de la economía política clásica inglesa o un punto de partida metodológico a partir de ésta, sino que es posible reconocer una Wirtschaftstheorie, una teoría económica que, bajo el cuño hegeliano de una Staatsökonomie -economía del Estado-, representaría un esfuerzo análogo a los desarrollados antes por J. H. G. Justi (Priddat 13). Erzsébet Rózsa ha argumentado sistemáticamente contra la hipótesis de Priddat, al sostener que "la teoría hegeliana de la economía [Wirtschaft] moderna no debe ser entendida como una economía [Ökonomie], sino como una filosofía de la economía [Wirtschaftphilosophie]" (Rózsa 182). Para Rózsa, "Hegel no fue un economista, no al modo de A. Smith, Say o Ricardo" (Ibíd), y, subsecuentemente, tampoco al modo de Justi, podemos suponer. Ahora bien, si para Priddat y Rózsa la discusión 
versa sobre la existencia o no de una Wirtschaftstheorie o una Wirtschaftphilosophie en la complejidad de la filosofía hegeliana, para Claudio Mario Aliscioni se trata más bien de comprender la función implícita pero específica que cumpliría el capital en la conformación de la representación hegeliana del presente:

Explícitamente al menos, Hegel nunca escribió una teoría del capital. Pero eso no significa en absoluto que ese concepto no sobrevuele, a veces como un espectro, toda su filosofía política, incluso desde los escritos tempranos. El capital, como sucede con otras categorías de todo el amplísimo universo hegeliano, representa aquel espacio no tematizado en la Filosofía del derecho, pero que sin embargo resulta imprescindible para la comprensión cabal de la obra (19).

La posición de Aliscioni, en principio, es la que más se acerca filosóficamente a la propuesta hegeliana. Pues esta última, dice José María Ripalda en su introducción a los Escritos de juventud, "desarrollará en su misma forma y estructura filosófica la anatomía oculta del capital como apogeo de la buena conciencia burguesa y potenciación a la vez que crítica de su destructiva acción" (Hegel 2003 30). Subsecuentemente, para Ripalda, no nos enfrentamos entonces a una aproximación hipotéticamente "neutra", que pretenda solo dar cuenta de una conceptualización de la economía política, sino que esta misma lectura implica, en el caso de Hegel, una interpretación crítica del capital y el capitalismo: "materialmente, tras haber leído a Adam Smith [concluye Ripalda], Hegel hará [...] un análisis crítico del capitalismo, que pertenece, aún hoy, a los más profundos que se han escrito" (Ibíd). Reconocer esta confrontación formaly material implica, por lo pronto, atender al contexto en el cual Hegel desarrolla sus análisis:

Hegel comenzó viviendo el sufrimiento de una época con señas contradictorias de identidad [...] el resultado era la reestructuración del individuo como "persona" (jurídica), emisario él mismo del producto cotidiano de sus manos y su inteligencia. Los hombres seguimos produciéndonos 
a nosotros mismos, pero en una enajenación sin rostro, abstracta, destructiva hasta de su base natural. Ninguna religión ha sido capaz de igualar jamás el totalitarismo de esta enajenación. La desmitologización absoluta en que culmina el programa tardoilustrado y hegeliano de una nueva mitología, alude, reproduciéndola, a esta estructura fundamental de la personalidad bajo el capital. [Por ello] la grandeza aún hoy imponente de Hegel consiste en que toda su vida fue un esfuerzo por llegar a comprender el capital (Ripalda 294).

El aspecto común de los trabajos de Rózsa, Aliscioni y Ripalda estriba en el reconocimiento de una crítica de la economía política del capitalismo en la filosofía hegeliana. A diferencia de la tradición del marxismo occidental, aquí no se trata de evaluar la crítica hegeliana desde la marxiana, sino de proyectar el desarrollo de la crítica hegeliana por sí mismo. Lo que desarrollaremos a continuación es cómo la conceptualización hegeliana de la economía política adquiere la forma de una crítica de los procesos de colonización de la modernidad que inaugura un debate presente hoy en diversas instancias analíticas de la modernidad.

\section{Hacia la economía política del colonialismo}

Los acontecimientos históricos, políticos y económicos que antecedieron, conformaron y sucedieron a las transformaciones de 1789-1848 no representan, por supuesto, un objeto de investigación exclusivo de la filosofía hegeliana. Gilles Campagnolo ha sostenido que, "desde el comienzo del mercantilismo hasta la era triunfal de la industrialización continental a gran escala, uno podría seguir [estos] cambios [históricos] en las características [del] Dr. Fausto" (Campagnolo 87). Mark D. White, por su parte, ha defendido la presencia de paralelos económicos, políticos y filosóficos entre los escritos de Adam Smith y la filosofía moral kantiana (2011). Más lejos llegará Howard Williams, al sostener que la filosofía kantiana ofrecería una "perspectiva universalista emancipatoria", en orden a establecer empíricamente el proyecto "autónomo" de 
la llustración europea (Williams 155). En principio, estas relaciones no comportan ningún excepcionalismo, pues, como ha mostrado Jorge Dotti, "[...] en el ambiente cultural germano, estas doctrinas se difundían directamente a través de traducciones o en reseñas y artículos, siendo sus principales agentes de divulgación los exponentes de la Popularphilosophie (Garve, Schlosser, Abbt, Iselin)" (Dotti 135).

El problema, a decir de Buck-Morss, es la perspectiva desde la cual se conceptualizó la economía política, pues desde Locke y Rousseau a Kant y Goethe nos enfrentaríamos a una sublimación de los discursos sobre la economía y la libertad, que paralela y paradójicamente omitirían cualquier referencia a las supresiones "realmente existentes" de las libertades económicas y políticas, por ejemplo, en los espacios coloniales. Para Buck-Morss, las condiciones realmente existentes de la modernidad aparecen justamente en la conceptualización hegeliana, producto de la atención que Hegel habría puesto en los acontecimientos revolucionarios de Haití a través de las publicaciones del periódico Minerva. En esta aproximación, de sustento prioritariamente filológico, la revolución desatada en Haití en 1789, y las radicalizaciones lideradas por François Toussaint-Louverture y Jean-Jacques Dessalines hasta 1804, habrían implicado un vuelco en la filosofía hegeliana hacia una conceptualización antropológica de la historia (Buck-Morss 114). Ahora bien, la precisión de Buck-Morss sobre la abstracción de las caracterizaciones ilustradas de las experiencias coloniales de la modernidad nos permite encauzar un punto de nuestra exposición: ¿qué diferencia hace tal o cual forma de caracterización de la economía política en relación con los procesos de colonización? Tomemos como ejemplo comparativo a Kant.

Según la caracterización kantiana, el dinero en su forma abstracta, representa una universalidad formal de intercambio de mercancías y de medida social del trabajo productivo. En su forma concreta, insistirá Kant en La paz perpetua, el dinero cumple una función de potestad, a través de la cual "esa fuente de financiación [el dinero] no es sospechosa para buscar, dentro o fuera del Estado, un fomento de la economía (mejora de los caminos, nuevas colonizaciones, creación de depósitos...)" (Kant 8). Es aquí que nos enfrentamos a un punto de inflexión. 
Para Kant, la colonización - como la construcción de carreteras o la creación de depósitos- implicaría hipotéticamente la posibilidad de aumentar la satisfacción de las necesidades sociales mediadas por el dinero. Para Hegel, el hecho de atisbar el comportamiento realmente existente del dinero, las relaciones comerciales y el colonialismo deriva en un problema diametralmente opuesto:

Cuando la sociedad civil se encuentra en actividad libre se entiende desde su interior con población e industria creciente[s]. Con la universalización de la conexión entre los hombres mediante sus necesidades y modos de preparar y procurar los medios para ellas [a saber, el dinero, das Geld] se acrecienta por una parte la acumulación de las riquezas [...] así como por otra parte la singularización y limitación del trabajo particular y con ella la dependencia y necesidad de la clase ligada a este trabajo (Hegel 243).

Esta relación, argumenta Hegel, "[...] pone de relieve que, en medio del exceso de la riqueza, la sociedad civil no es lo bastante rica, esto es, no posee bastante con el patrimonio que le es particular como para subsumir el exceso de la pobreza y el surgimiento de la plebe [Pöbel]" (Id. 245). Aquello que en el Kant de La paz perpetua es tematizado como una posibilidad, para Hegel representa una necesidad estructural de las sociedades modernas,

La sociedad civil, ante todo esta determinada sociedad [diese bestimmte Gesellschaft], es empujada más allá de sí por dicha dialéctica [durch diese ihre Dialektik] para buscar fuera de ella los consumidores en otros pueblos que respecto de ella se encuentran atrasados en los medios en que ella resulta excedentaria o en general en industria, etc., y con ello los medios de subsistencia necesarios (Id. 246).

Con estos tres fragmentos Hegel inaugura un problema ausente en la filosofía clásica alemana, a saber, ¿por qué la experiencia económica de la modernidad debe por necesidad aparecer como una experiencia colonial? Y, por supuesto, esto implica una pregunta paralela, ¿cómo llegó Hegel a formular esta relación? 
Diego Guerrero ha visto en la conceptualización hegeliana de la sociedad civil no solo una expresión de las relaciones de riqueza-(lujo)/ necesidad-(pauperismo), sino también una apropiación de las tesis económicas sobre subconsumo y sobreproducción, esgrimidas por Sismondi como crítica a la Ley de Say (Guerrero 95). Paralelamente, en su edición de las Vorlesungen über Rechtsphilosophie, Karl-Heinz Ilting enfrenta el problema de la dialéctica de la sociedad civil mediante una significación que podría ser atendida como demográfica. Si bien llting no desarrollará explícitamente una interpretación precisa, da a entender su posición al titular los parágrafos dedicados a este problema bajo el rótulo de "Colonisation bei Überzahl der Population" (Hegel 1973 I 323).

Las perspectivas de Guerrero e Ilting dejan ver una doble causalidad: en primera instancia, el reconocimiento de la hipótesis hegeliana de la dialéctica de la sociedad civil como causa inmediata del colonialismo y, en segunda, la elaboración de una hipótesis económica (subconsumo/ sobreproducción) y/o demográfica (sobrepoblación) como estructura de la dialéctica de la sociedad civil. Douglas Moggach (Moggach 5) y Briger Priddat (Priddat 11) han insistido, respectivamente, en que Hegel habría incorporado las primeras críticas liberales de la economía política propuestas por Sismondi y Malthus, haciendo plausibles las hipótesis de Guerrero e Ilting, respectivamente. Por lo pronto, con la primera causa del colonialismo esgrimida por Guerrero e Ilting, es decir, que éste sea estrictamente una consecuencia de la dialéctica de la sociedad civil, estamos de acuerdo. Sin embargo, las hipótesis estrictamente económicas y demográficas que animan sus propuestas merecen una aclaración, pues, como sostiene Lisa Herzog, "no hay evidencia directa de estas influencias" en la conceptualización hegeliana de la economía política (Herzog 56).

Sabemos, por una carta enviada a Leopold von Henning, fechada el 19 de marzo de 1825, que Hegel consideraba absolutamente necesario el uso de la Historie des Française de Sismondi para el desarrollo de sus lecciones sobre filosofía de la historia universal (1962 330). Sin embargo, no contamos a nuestro haber ninguna mención adicional, en los materiales filológicos disponibles, que den a enten- 
der una lectura de sus escritos económicos (Erdös 76). Desde esta perspectiva, suponer que la deducción hegeliana de la dialéctica de la sociedad civil-burguesa derive de una interpretación personal de Sismondi, además de implicar una exageración, pareciera tener en la argumentación de Guerrero la función de relativizar la influencia de Hegel sobre Marx, para dar paso a una construcción genealógica de la crítica marxiana de la economía política a partir de las tesis de subconsumo/sobreproducción desarrolladas por Sismondi. Sabemos, también, que en relación a la demografía de fines del siglo XVIII y comienzos del siglo XIX, Hegel conocía las tesis de Johann Süssmilch a través de los comentarios y críticas esgrimidas por Kant y Herder (Spencer 29). Sin embargo, además de la propuesta de Ilting, solo es posible encontrar una mención, por lo pronto indirecta, en relación a la hipotética sobrepoblación de los espacios económicos modernos como causa directa de la colonización. En 1822/24, Gustav Hotho anotaba que: "Cuando la pauperización interna alcanza su [más alto] grado, [y] un pueblo tiene más individuos de los que puede sustentar, sucede la colonización" (Hegel 1973 III 705). A nuestro parecer, Ilting incurre en una confusión, pues, si bien es cierto tanto Hegel como Hotho entienden que en un estado de desarrollo de la industria de la sociedad civil la población aumenta proporcionalmente, Hotho precisa que la (literalmente) sobre-población se ve en la necesidad de proyectar una práctica colonial al enfrentar una imposibilidad de satisfacción de necesidades coordinadas a través del consumo: en este caso, la alimentación. Una hipótesis de este tipo constituye una aproximación más fiel a las tesis de Sismondi sobre subconsumo/sobreproducción que a las tesis esgrimidas por Malthus sobre población/alimentación en sus Principios. Desde esta perspectiva, Ilting incurre en el error de confundir una causa empíricamente inmediata (la sobrepoblación) con una causa lógicamente estructural (subconsumo/sobreproducción).

Para Shlomo Avineri, no se trata de un problema de interpretación de la hipotética influencia de Sismondi o Malthus (directa o indirecta) en Hegel, sino de los alcances históricos y filosóficos que implica la conceptualización hegeliana de la dialéctica de la sociedad civil. Subconsumo/sobreproducción y sobrepoblación constituyen históricamente una dimensión "inherente y endémica de la sociedad 
moderna" (Avineri 146); pero, filosóficamente, implican la estructuración causal del "único momento del sistema en que Hegel erige un problema, y [luego] lo deja abierto" (Id. 154). Ese problema abierto es, por cierto, el del imperialismo. El imperialismo se vuelve una problemática aporética para el desarrollo conceptual en el marco teórico del marxismo temprano, en tanto el fenómeno viene aparejado con el desarrollo del mercado mundial. La inclusión del concepto dentro de la exposición crítica del capital encuentra puntos de conflicto a causa de la naturaleza propiamente historiográfica del fenómeno colonial. En Marx, la inclusión del tema en los capítulos XXIV y XXV de El Capital intenta dar cuenta de ello, pero, a la vez, parece no estar en consonancia con el modo de exposición autodesplegante de la obra. La influencia de Hegel, entonces, para la explicación del fenómeno del colonialismo e imperialismo se vuelve en objeto de análisis para los teóricos marxistas de principios del siglo XX.

\section{Hegel, el imperialismo y el marxismo occidental}

La conceptualización hegeliana de la sociedad civil, sostiene Alfred O. Hirschman, de una parte, proyecta un conjunto de problemas ausentes en la categorización marxiana de la crítica de la economía política $y$, de otra, anticipa las propuestas esgrimidas a comienzos del siglo XX por Rudolf Hilferding, John A. Hobson, Rosa Luxemburg, Nicolai Bujarín e, incluso, Vladimir Lenin (Hirschman 4).

Para Hirschman, las anticipaciones de Hegel, omitidas por el marxismo de comienzos del siglo XX, evidencian en definitiva la ausencia de una teoría marxiana del colonialismo y del imperialismo. Marx, sostiene Hirschman, conocía perfectamente bien los pasajes hegelianos dedicados a la dialéctica interna de la sociedad civil; sin embargo, habría reprimido esta representación del presente debido a la confianza en la inminencia de una revolución proletaria europea como contención de los procesos empíricos de desarrollo del colonialismo (Ibíd). Para el Lenin de El desarrollo del capitalismo en Rusia, Hegel representa un antecedente idealista de la formación epistemológica 
del pensamiento marxiano y de las críticas materialistas de Ludwig Feuerbach. Posteriormente, sostiene Kevin Anderson, el Lenin del exilio de 1914-1917 encontró en Hegel un antecedente lógico para sus más de ochocientas páginas reunidas en las Notas sobre el imperialismo que, posteriormente, vertería sintéticamente en El imperialismo, fase superior del capitalismo (Anderson 123). La influencia de Hegel en el Lenin del exilio, sin embargo, se debe a un vuelco epistemológico antes que a un análisis de las propias tesis hegelianas sobre el colonialismo (Id. 28), vuelco que se fundamenta en una interpretación singular, hegeliana digamos, de los capítulos XXIV y XXV de El Capital, es decir, de los análisis marxianos de La llamada acumulación originaria y La teoría moderna de la colonización, respectivamente.

Lenin, en efecto, focalizó sus investigaciones en las Lecciones sobre filosofía de la historia universal y en la Ciencia de la lógica, omitiendo prácticamente todo comentario referido a la Filosofía del derecho y, por tanto, a la conceptualización hegeliana de la dialéctica de la sociedad civil-burguesa. Esta focalización en la Lógica ha sostenido, concluye Anderson, el debate sobre la carencia de originalidad de las tesis de Lenin sobre el imperialismo en relación al trabajo de Bujarín publicado el mismo año, pero terminado ya hacia 1915.

Ahora bien, y para ser justos con la posición analítica de Lenin, éste al parecer sí conocía la conceptualización hegeliana, pero a partir de su exposición en las Lecciones sobre filosofía de la historia universal. Al entablar relación con éstas, escribe Lenin: "La migración a América elimina[ría] el 'descontento' y 'garantiza[ría] la existencia continuada del orden civil contemporáneo", pero, agrega, el "Zustand de [esta migración] es '[la] riqueza y [la] pobreza" (Lenin 292). Al margen de estas observaciones, Lenin anotó, eclécticamente, "Cf. Plejánov". Si acaso con esto Lenin se refería al opúsculo de fines del siglo XIX, es difícil saberlo. Sin embargo, podemos suponerlo en el orden de establecer la continuidad de las discusiones sobre la conceptualización hegeliana del colonialismo. Pues Plejánov no solo identifica esta dimensión, sino que además fue, en estricto rigor, el primer intérprete de la filosofía hegeliana en poner de relieve esta dimensión de su conceptualización del presente, a pesar de la aparente desatención de Marx: 
Hegel [...] que en una sociedad basada en la propiedad privada, el crecimiento de la riqueza en una parte va acompañado inevitablemente del crecimiento de la pobreza en otra parte. Así lo dice expresamente en su Filosofía del Derecho (§ 245). Para usar sus palabras, esta dialéctica —es decir, un descenso del nivel de vida de la mayoría de la población como resultado del cual ya no puede satisfacer adecuadamente sus necesidades, y que concentra la riqueza en pocas manos- debe llevar necesariamente a una situación en la que la sociedad civil, no es suficientemente rica, a pesar del exceso de riqueza; es decir, que no posee los medios suficientes para evitar el exceso de pobreza y la formación de la plebe (des Pöbels). El resultado es que la sociedad civil se ve forzada a salir de sus propias fronteras y a buscar nuevos mercados, a recurrir al comercio internacional y a la colonización. De todos los contemporáneos de Hegel, Fourier fue el único que se distinguió por una claridad similar en el punto de vista y una buena comprensión de la dialéctica de las relaciones económicas burguesas (164).

Ahora bien, a la misma tesis que Hirschman adscribe David MacGregor al sostener que "el dilema abierto por el eminente economista, ha sido ignorado desde entonces por los marxistas (y por muchos hegelianos)". Esta hipótesis se sostiene, de acuerdo a Perry Anderson, en el hecho que, tras la generación de Lenin, la figura de Hegel no fue más que un lejano espectro dentro de los márgenes del marxismo occidental (cf. Anderson 78): lo que explicaría, en algún grado, la ausencia analítica identificada por MacGregor, al menos dentro de los márgenes de la tradición marxista.

A la hipótesis inicial de Hirschman subyace otra de mayor alcance y radicalidad: no se trataría, por lo pronto, de demostrar la ausencia de una teoría específica del colonialismo en la crítica marxiana de la economía política, sino de demostrar la existencia de una tesis hegeliana del desarrollo histórico del capitalismo, la competencia y la dependencia, que permitiría, incluso, contribuir a la comprensión del 
estancamiento de las economías dependientes latinoamericanas de la década de 1960 y 1970. Para Hirschman, demostrar la especificidad de la interpretación hegeliana del colonialismo implica subvertir las hipótesis esgrimidas por Guerrero y Moggach, de una parte, y las de Priddat e llting, de otra:

De hecho, el primer trabajo económico que impugnó la 'Ley de Say' y propuso una noción generalizada de sobreproducción, los Nouveaux principles de l'economie politique [sic] de Sismondi, fue publicado en 1819 y los Principios de economía política de Malthus serían publicados un año después. Pero Hegel difícilmente podría haber estado familiarizado con estos trabajos en su momento, y el 'exceso de producción' del parágrafo 245 parece ser más bien un pensamiento independiente de Hegel deducido a partir de la polarización de la sociedad civil entre ricos y pobres, un tema importante en los parágrafos precedentes. Más notable aún es el salto de Hegel desde los oprobios de la sobreproducción generalizada en una economía cerrada [nacional] hacia su solución en la forma de la expansión mercantil y colonial: ni Sismondi ni Malthus pudieron deducir una conclusión tal, y Hegel escribió [esto] justo antes del primer oleaje británico sobre los países latinoamericanos recientemente independizados en los años 20'. En ambos casos, las conclusiones de Hegel están, por tanto, particularmente arraigadas en el sorprendente uso imaginativo de su método dialéctico (3).

El problema, sostiene David Harvey, no estriba en que el marxismo, en cuanto marxismo, deba o no hacerse cargo de la conceptualización hegeliana del colonialismo (sea desde la perspectiva del subconsumo, la sobreproducción o la intensificación demográfica, desde la perspectiva de Plejánov o Lenin): sino que, y muy por el contrario, es el marxismo, en tanto crítica de la economía política, una perspectiva analítica que debe atender temáticamente el nudo abierto por Hegel a través de un análisis crítico del capitalismo. Desde la perspectiva de Harvey el problema es algo más preciso 
y, en términos de exposición, aglutina todos los objetivos que se discuten en esta investigación:

[Hegel] examina el desarrollo interno de la población y de la industria dentro de la sociedad civil, y como Marx, detecta una 'dialéctica interna' que produce una creciente acumulación de riqueza en un polo y una creciente acumulación de miseria en el otro. La sociedad burguesa parece incapaz de detener esta creciente polarización y su acompañamiento, la creación de un canalla miserable, por medio de cualquier transformación interna de sí misma. Por tanto se ve obligada a buscar alivio externo [...] Más particularmente, una sociedad civil 'madura' se ve impulsada a fundar colonias para abastecer a su población con nuevas oportunidades y para abastecerse 'a sí misma con una nueva demanda y campo para su industria'. Hegel propone, en pocas palabras, soluciones imperialistas y coloniales a las contradicciones internas de una sociedad civil fundada en la acumulación de capital. En forma hasta cierto punto poco característica, Hegel deja abierta la relación exacta entre los procesos de transformación interna y externa, y no indica si la sociedad civil puede o no resolver permanentemente sus problemas internos por medio de la expansión espacial. Con o sin intención, esta es la pregunta que quedó pendiente en el capítulo de Marx sobre la colonización. La 'transformación externa' puede proporcionar nuevos mercados y nuevos campos para la industria solo al precio de volver a crear relaciones capitalistas de propiedad privada y una capacidad para apropiarse del plustrabajo de otros (Harvey 417).

Como podemos notar en el análisis de Harvey, las hipótesis de Marx —y del marxismo - no resolverían el problema propuesto por Hegel ( $y$, por lo pronto, evaluar tal relación cae completamente fuera del foco de esta investigación); por ello, para Harvey, "aún queda por construir una respuesta comprensible e irrefutable al problema que planteó Hegel tan claramente hace tantos años" (Id. 418). 


\section{Conclusión}

Lo que está en juego, desde la perspectiva de Harvey, es la fundamentación lógica e histórica del llamado desarrollo geográfico desigual del capitalismo. Sin embargo, en las páginas precedentes hemos apostado por ordenar el recorrido del debate antes que por una defensa de la propuesta de Harvey. En este contexto, el análisis hegeliano del colonialismo capitalista —más allá de constituir o no una defensa y/o legitimación - nos enfrenta nuevamente al problema del análisis de la composición y límites de los mercados capitalistas nacionales y su expansión virtualmente infinita. Por supuesto, siguiendo la misma línea hegeliana de interpretación, la expansión espacial cuantitativa es empíricamente imposible, razón por la cual, en última instancia, la interpelación hegeliana estriba en la transformación cualitativa e intensiva de los mercados nacionales e internacionales transidos por la dependencia política y económica. En un mundo cada vez más complejo, escenario de diversas tesis convergentes $y / o$ divergentes respecto a la unicidad diferencial de los mercados, este problema sigue siendo de suma relevancia filosófica, sociológica e histórica. Las tesis sobre la urbanización planetaria, el sur global, el sistema-mundo, la globalización y un largo etcétera, constituyen esfuerzos por dar cuenta y conceptualizar el problema abierto y acaso inaugurado por Hegel a comienzos del siglo XIX, razón por la cual constituye éste un punto infranqueable en la precisión disciplinar del largo recorrido de la crítica de la economía política.

La deducción hegeliana parece dar paso a un modo de construcción genealógico que tiene influencia directa en las lecturas, tanto de subconsumo/sobreproducción de Sismondi, como en la concepción marxista del auge de las relaciones imperialistas. El gesto hegeliano vendría a pensar el gesto económico como una filosofía de la economía [Wirtschaftphilosophie], según la caracterización de Rózsa, que trata de comprender las funciones implícitas de las relaciones jurídicoeconómicas desde contextos personológicos hasta la totalidad de la sociedad civil. La lectura de este esfuerzo hegeliano, que da paso a los posteriores análisis sobre la lógica asimétrica del capital, será un punto de partida para la dilucidación póstuma de los fenómenos estructurales de colonización e imperialismo. 


\section{Bibliografía}

Aliscioni, Claudio Mario. El capital en Hegel. Estudio sobre la lógica económica de la Filosofía del derecho. Rosario: Homo Sapiens, 2009.

Anderson, Kevin. Lenin, Hegel, and Western Marxism. A Critical Study. Illinois: University of Illinois Press, 1995.

Anderson, Perry. Consideraciones sobre el marxismo occidental. México: Siglo XXI, 2011.

Aricó, José. Nueve lecciones sobre economía y política en el marxismo. Buenos Aires: FCE, 2012.

Arrighi, Giovanni. El largo siglo XX. Dinero y poder en los orígenes de nuestra época. Madrid: Akal, 2014.

Avineri, Shlomo. Hegel's Theory of the Modern State. Cambridge: Cambridge University Press, 1976.

Beiser, Frederick. Hegel. Routledge: New York, 2011.

Buck-Morss, Susan. Hegel, Haití y la historia universal. México: FCE, 2013.

Carter, William. "Faust's Begehren: Revisiting the History of Political Economy in Faust II", Goethe Yearbook 11 (2014): 103-128.

Campagnolo, Gilles. Criticism of Classical Political economy. Menger, Austrian Economics and the German Historical School. New York: Routledge, 2010.

Dotti, Jorge. Dialéctica y derecho. El proyecto ético-político hegeliano. Buenos Aires: Hachette, 1983.

Durkheim, Émile. La división del trabajo social. Madrid: Akal, 2001.

Erdös, Ernst. "Hegels politische Oekonomie im Verhältnis zu Sismondi", Hegel-Jahrbuch (1986): 75-86.

Guerrero, Diego. Sismondi, precursor de Marx. Madrid: Maia, 2011.

Harvey, David. Los límites del capitalismo y la teoría marxista. México: FCE, 1990.

Hegel, G. W. F. Correspondance III. Paris: Gallimard, 1962.

Hegel, G. W. F. Fundamentos de la filosofía del derecho. Madrid: Libertarias, 1993.

Hegel, G. W. F. Escritos de juventud. Madrid: FCE, 2003. 
Hegel, G. W. F. Vorlesungen über Rechtsphilosophie 1818-1831. Herausgegeben von Karl-Heinz Ilting. 4 Bände. Stuttgart: Frommann-Holzboog, 1973.

Herzog, Lisa. Inventing the Market. Smith, Hegel, \& Political Theory. Oxford: Oxford University Press, 2013.

Hirschman, Alfred O. "On Hegel, Imperialism and Structural Stagnation", Journal of Development Economics 3/1 (1976): 1-8.

Hobsbawm, Eric. La era de la revolución, 1789-1848. Barcelona: Crítica, 2011.

Kant, Immanuel. Sobre la paz perpetua. Madrid: Técnos, 1998.

Lukács, Georg. El joven Hegel y los problemas de la sociedad capitalista. México: Grijalbo, 1963.

Lenin, Vladimir. Cuadernos filosóficos. Buenos Aires: Ediciones Estudio, 1972.

MacGregor, David. Hegel, Marx, and the English State. Toronto: University of Toronto Press, 1996.

Marcuse, Herbert. Razón y revolución. Hegel y el surgimiento de la teoría social. Madrid: Alianza, 2010.

Moggach, Douglas. The New Hegelians: Politics and Philosophy in Hegelian School. Cambridge: Cambridge University Press, 2006.

Plejánov, Georgi. "En el $60^{\circ}$ aniversario de la muerte de Hegel", Revista Colombiana de Sociología 35/1 (2012): 153-175.

Priddat, Birger. Hegel als Ökonom. Berlín: Duncker \& Humblot, 1990.

Polanyi, Karl. La gran transformación. Los orígenes económicos y políticos de nuestro tiempo. México: FCE, 1992.

Ripalda, José María. La nación dividida. Raíces de un pensador burgués: G. W. F. Hegel. México: FCE, 1978.

Rosenfield, Denis. Política y libertad. La estructura lógica de la Filosofía del Derecho de Hegel. México: FCE, 1989.

Rózsa, Erzsebet. Hegels Konzeption praktische Individualität. Münster: Mentis, 2007.

Smith, Adam. La riqueza de las naciones. Madrid: Alianza, 1996.

Spencer, Vicki. Herder's Political Thought. A Study of Language, Culture, and Community. Toronto: University of Toronto Press, 2012.

Weber, Max. Die protestantische Ethik und der 'Geist' des Kapitalismus. Wiesbaden: Springer, 2016. 
HEGEL Y LA CRÍTICA DE LA ECONOMÍA POLÍTICA DEL COLONIALISMO. LA RECEPCIÓN DE UN DEBATE INCONCLUSO / Narváez y Pulgar

White, Mark D. Kantian Ethics and Economics. Autonomy, Dignity and Character. Stanford: Stanford University Press, 2011.

Williams, Howard. "Colonialism in Kant's Political Philosophy", Diametros. An online Journal of Philosophy 39 (2014): 154-181. 